\title{
Is high T-1 slope a significant risk factor for developing interlaminar bony fusion after cervical laminoplasty? A retrospective cohort study
}

\author{
Takeshi Oichi, MD, ${ }^{1}$ Yasushi Oshima, MD, PhD, ${ }^{1}$ Hiroyuki Oka, MD, PhD, ${ }^{1}$ Yuki Taniguchi, MD, PhD, ${ }^{1}$ \\ Hirotaka Chikuda, MD, PhD, ${ }^{1}$ Yoshitaka Matsubayashi, MD, ${ }^{1}$ Katsushi Takeshita, MD, PhD, ${ }^{2}$ and \\ Sakae Tanaka, MD, PhD'
}

'Department of Orthopaedic Surgery, The University of Tokyo Hospital, Tokyo; and 'Department of Orthopaedic Surgery, Jichi Medical University, Tochigi-ken, Japan

\begin{abstract}
OBJECTIVE Several investigators have reported the occurrence of interlaminar bony fusion after cervical laminoplasty, which is reportedly associated with reduced postoperative cervical range of motion (ROM). However, to the authors' knowledge, no previous study has investigated the characteristics of patients who were likely to develop interlaminar bony fusion after cervical laminoplasty. Therefore, the objective of this study was to investigate the risk factors for interlaminar bony fusion in patients with cervical spondylotic myelopathy (CSM) following cervical laminoplasty and to investigate the effect of interlaminar bony fusion on surgical outcomes.

METHODS The authors retrospectively reviewed data from 92 patients with CSM (63 men and 29 women) after cervical laminoplasty. The presence of interlaminar bony fusion was evaluated by functional radiographs 2 years after surgery. The patients were divided into 2 groups according to the presence of postoperative interlaminar bony fusion: a fusion group (at least 1 new postoperative interlaminar bony fusion) and a nonfusion group (no new interlaminar bony fusion). Potential risk factors for postoperative interlaminar bony fusion were assessed, including diabetes mellitus, smoking status, whether the C-2 lamina was included in the surgical treatment, $\mathrm{C} 2-7 \mathrm{Cobb}$ angle in each cervical position, preoperative cervical ROM, and T-1 slope. The differences in each variable were compared between the fusion and nonfusion groups. Thereafter, multivariate logistic regression analysis was performed to identify the risk factors for postoperative interlaminar bony fusion. For surgical outcomes, the recovery rate based on Japanese Orthopaedic Association scores and the reduction rate of cervical ROM were evaluated 2 years after surgery.
\end{abstract}

RESULTS Interlaminar bony fusion was observed in 60 cases, 52 of which were observed at the C2-3 level. Patients in the fusion group were significantly older, had a significantly larger $\mathrm{C} 2-7$ angle in flexion, and had a significantly lower preoperative cervical ROM than those in the nonfusion group. A high T-1 slope was significantly more frequent in the fusion group. Multivariate analysis revealed that the significant risk factors for postoperative interlaminar bony fusion were high T-1 slope (odds ratio 4.81; $p=0.0015$ ) and older age (odds ratio 1.05; $p=0.025$ ). The Japanese Orthopaedic Association recovery rate in patients with interlaminar bony fusion did not differ significantly from those without bony fusion ( $45 \%$ vs $48 \% ; p=0.73$ ). However, patients with bony fusion showed significantly reduced postoperative cervical ROM compared with those without bony fusion ( $50 \%$ vs $25 \%$; $p<0.001)$.

CONCLUSIONS High T-1 slope and older age were significant risk factors for developing interlaminar bony fusion after cervical laminoplasty in patients with CSM. Interlaminar bony fusion was associated with reduced postoperative cervical ROM, but it did not affect neurological outcomes.

https://thejns.org/doi/abs/10.3171/2017.3.SPINE16883

KEY WORDS cervical spine; cervical spondylotic myelopathy; interlaminar bony fusion; T-1 slope; cervical laminoplasty; Japanese Orthopaedic Association; recovery rate

ABBREVIATIONS $\mathrm{Cl}=$ confidence interval; $\mathrm{CSM}=$ cervical spondylotic myelopathy; HRQOL = health-related quality of life; JOA = Japanese Orthopaedic Association; $\mathrm{OPLL}=$ ossification of the posterior longitudinal ligament; $\mathrm{OR}=$ odds ratio; $\mathrm{ROM}=$ range of motion.

SUBMITTED July 28, 2016. ACCEPTED March 16, 2017.

INCLUDE WHEN CITING Published online September 15, 2017; DOI: 10.3171/2017.3.SPINE16883. 
$\mathrm{C}$ ERVICAL laminoplasty is a well-established surgical procedure with satisfactory long-term clinical outcomes in patients with cervical spondylotic myelopathy (CSM)., ${ }^{1,116}$ However, cervical laminoplasty is associated with some postoperative complications, including C-5 palsy ${ }^{2}$ and axial symptoms. ${ }^{20}$ Furthermore, several investigators have reported the occurrence of interlaminar bony fusion after cervical laminoplasty ${ }^{5,6,10,11,16,19}$ at a rate of 53\%-66\%, with marked frequency at the C2-3 level. 5,6 , $10,11,16$ Postoperative interlaminar bony fusion is reportedly associated with reduced postoperative cervical range of motion (ROM) ${ }^{5,6,16}$ To the best of our knowledge, no previous study has investigated the characteristics of patients who were likely to develop interlaminar bony fusion after cervical laminoplasty. Therefore, this study aims to identify the risk factors for developing interlaminar bony fusion after cervical laminoplasty. We further investigated whether postoperative interlaminar bony fusion affects surgical outcomes.

\section{Methods}

We retrospectively reviewed prospectively collected data from 124 patients with CSM who underwent cervical laminoplasty at our institution between January 2000 and June 2012. We did not include patients who were treated with laminectomy or those with preoperative interlaminar bony fusion, a history of anterior decompression and fusion, ossification of the posterior longitudinal ligament (OPLL), fused vertebrae (e.g., diffuse idiopathic skeletal hyperostosis or ankylosing spine), cerebral palsy, exacerbation of CSM due to trauma, cervical spondylotic amyotrophy, polio, congenital anomaly of the cervical spine, rheumatoid arthritis, or spastic torticollis. We further excluded 32 patients due to the following reasons: short follow-up periods of less than 2 years $(n=10)$, incomplete chart data $(\mathrm{n}=8)$, and lack of radiological data $(\mathrm{n}=14)$. Finally, 92 patients with CSM (63 men and 29 women) were enrolled in this study. The study protocol was approved by the Clinical Research Support Center of The University of Tokyo Hospital. All participating patients provided written informed consent. The diagnosis of CSM was based on both neurological examination by board-certified spine surgeons and MRI findings. All patients underwent a double-door laminoplasty that involved midsagittal splitting of the spinous process, as described by Kurokawa et al. ${ }^{14}$ and wore a soft collar for 1-2 weeks postoperatively to relieve pain.

\section{Clinical Outcomes}

Neurological status before and 2 years after surgery was evaluated using the Japanese Orthopaedic Association (JOA) scores (total points, 17). ${ }^{8}$ The recovery rate 2 years after surgery was calculated according to the following formula: Recovery rate $(\%)=$ (postoperative JOA score - preoperative JOA score)/(17 [full score] - preoperative JOA score) $\times 100(\%){ }^{4}$

\section{Radiological Evaluation \\ CT Measurements}

Cervical CT scans were obtained for all patients before surgery with the subject in a comfortable supine position and gazing at the ceiling. The T-1 slope was usually measured using full-standing radiographs; ${ }^{13}$ however, in our cohort, there were many cases $(n=42)$ in which accurate measurement of the T-1 slope on cervical radiographs was difficult due to the interference of the shoulder, as reported previously. ${ }^{9}$ Alternatively, we measured the T-1 slope using 3D CT scans, which has been reported to significantly correlate with the measurements obtained using radiographs. ${ }^{9}$ The T-1 slope was measured as the angle between a horizontal line and the superior endplate of T-1, in the same manner as described previously (Fig. 1A). ${ }^{9}$ The validity of T-1 slope measurement on CT scans in this study was examined by calculating the correlation coefficient between the T-1 slope on a CT scan and that on a radiograph using the cases in which both types of data were available $(n=50)$. A T-1 slope $\geq 25^{\circ}$ was defined as high T-1 slope and a T- 1 slope $<25^{\circ}$ was defined as low T- 1 slope..$^{13}$ The presence of OPLL was assessed using 3D CT. Cases in which it was difficult to distinguish between OPLL and bony spur were not defined as OPLL. This study excluded patients with OPLL and those with fused vertebrae.
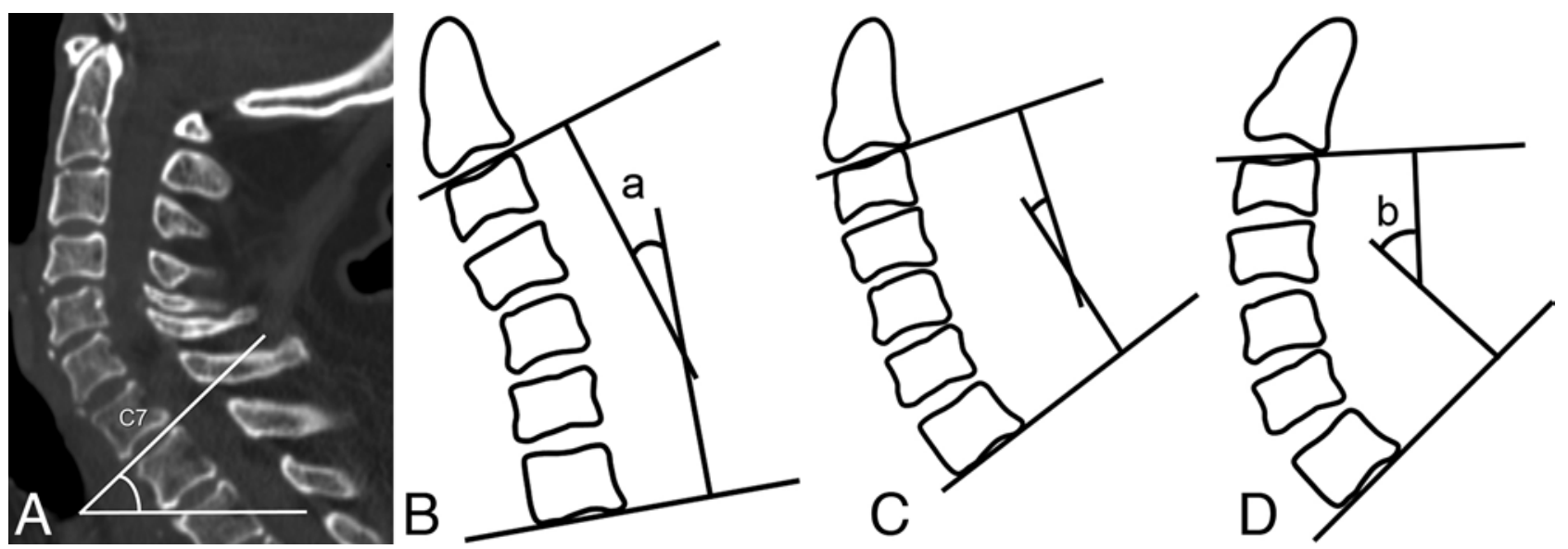

FIG. 1. A: Measurement of the T-1 slope. B: C2-7 angle in flexion position. C: C2-7 angle in neutral position. D: C2-7 angle in extension position. Cervical range of motion $=a+b$. 


\section{Radiograph Measurements}

Flexion-extension lateral radiographs were taken for each patient both preoperatively and 2 years after surgery. The C2-7 angle, determined by tangential lines on the posterior edge of the $\mathrm{C}-2$ and $\mathrm{C}-7$ bodies, was measured on lateral radiographs in maximal flexion, neutral, and maximal extension positions (Fig. 1B-D). Cervical ROM was defined as the sum of the $\mathrm{C} 2-7$ angles seen during flexion and extension on lateral radiographs. The reduction rate of cervical ROM was calculated according to the following formula: Reduction rate $(\%)=$ (preoperative cer-

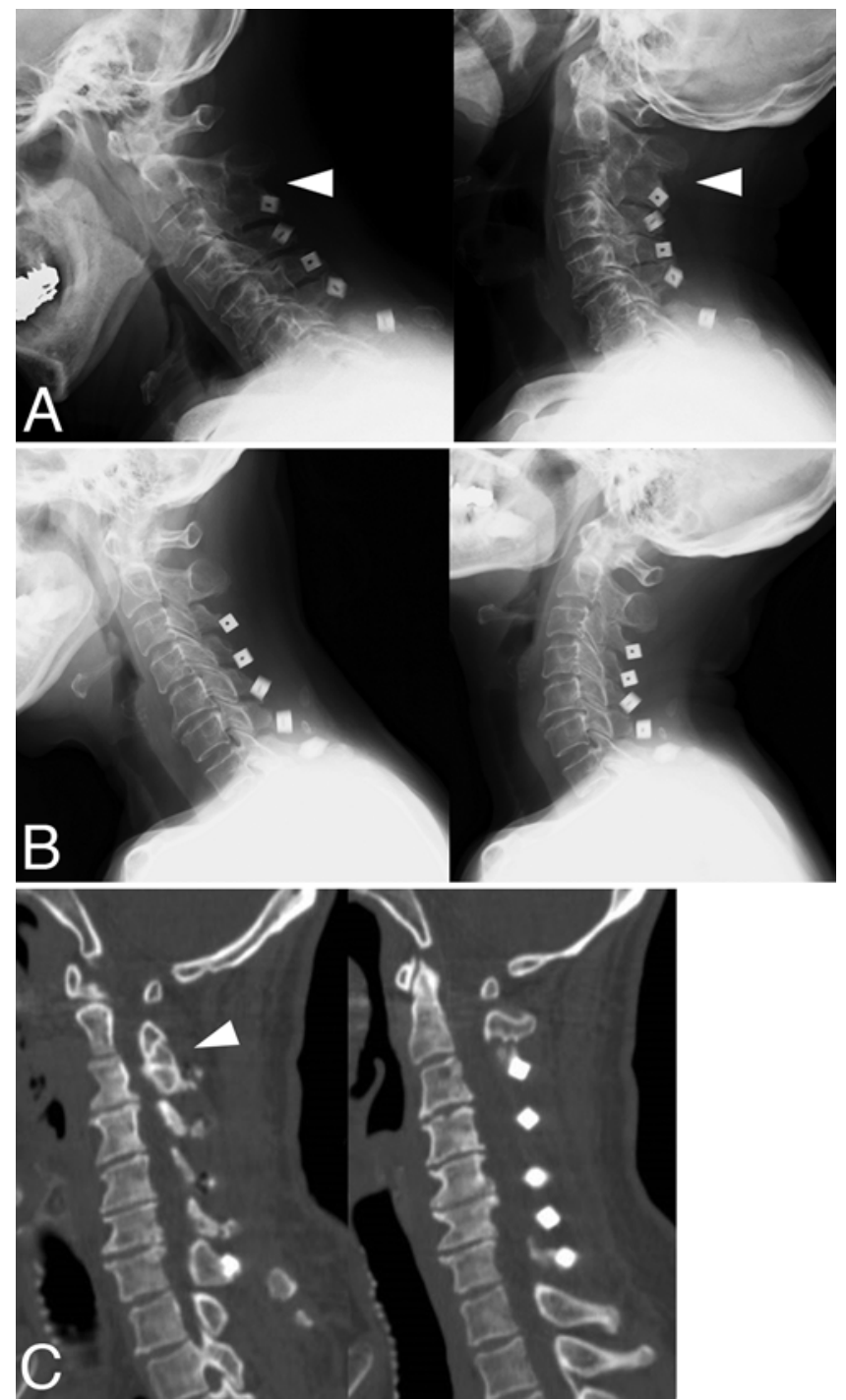

FIG. 2. Functional radiographs and CT scans of the cervical spine obtained 2 years after surgery are shown from representative cases with interlaminar bony fusion and without bony fusion. A: Apparent interlaminar bony fusion is observed at the C2-3 level (arrowheads) in a 68-yearold man with CSM and postoperative interlaminar bony fusion. B: Interlaminar movements in all laminae are observed in a 72-year-old woman with CSM without postoperative interlaminar bony fusion. C: Parasagittal (left) and midsagittal (right) CT scans of the cervical spine obtained 2 years after surgery in a 69-year-old woman with CSM. Parasagittal CT scan showed the presence of interlaminar bony fusion at the C2-3 level (arrowhead), and midsagittal CT scan showed no coexistent OPLL or diffuse idiopathic skeletal hyperostosis. vical ROM - postoperative cervical ROM)/(preoperative cervical $\mathrm{ROM}) \times 100 \%$.

As previously reported, 5,6 the presence of interlaminar bony fusion from occipital bone to $\mathrm{C}-7$ was evaluated using flexion-extension lateral radiographs both preoperatively and 2 years after surgery. If there were apparent interlaminar bony fusions or no interlaminar movement on functional radiographs, the patients were designated as having interlaminar bony fusions (Fig. 2A). If there were interlaminar movements in all laminae on functional radiographs, the patients were designated as not having interlaminar bony fusions (Fig. 2B). We divided the patients into 2 groups according to the presence of postoperative interlaminar bony fusion; these consisted of a fusion group (at least 1 new postoperative interlaminar bony fusion; Fig. 2C) and a nonfusion group (no new interlaminar bony fusion). Patients with preoperative interlaminar bony fusion and fused vertebrae were not included in our study.

\section{Other Data Collected}

Other demographic variables, including diabetes mellitus and smoking status (current or not), that could potentially affect the development of interlaminar bony fusion, as well as whether the C-2 lamina was included in the surgical treatment, were examined.

\section{Statistical Analysis}

Differences in both radiological and clinical variables between the fusion and nonfusion groups were compared. Radiological variables included T-1 slope (high or low), C2-7 angle in each cervical position (flexion, neutral, and extension), and preoperative cervical ROM. Demographic variables included age, sex, diabetes mellitus, smoking status, and involvement of the C-2 lamina. For surgical outcomes, the JOA recovery rate and the rate of reduction of cervical ROM were compared between the fusion and nonfusion groups. Among patients in whom the T-1 slope was measurable from both the $\mathrm{CT}$ scan and the radiograph $(n=50)$, the correlations of T-1 slopes between those obtained from the CT scan and those from the radiograph were analyzed using Pearson's correlation coefficient.

For continuous variables, 2-group comparisons were performed using the Student t-test or the Wilcoxon ranksum test, as appropriate. Categorical variables were compared between the groups using the chi-square test or Fisher's exact probability test, as appropriate. A multiple logistic regression model yielding the odds ratio (OR) and $95 \%$ confidence interval (CI) was used to identify significant risk factors for postoperative occurrence of interlaminar bony fusion. Variables with a $\mathrm{p}$ value $<0.10$ in the univariate analyses were entered into the multiple logistic regression model. The variance inflation factor was used to check for multicollinearity in the model. Data analyses were performed using the JMP software, version 9.0 (SAS Institute); $\mathrm{p}$ values $<0.05$ were considered significant. All tests were 2-tailed.

\section{Results}

\section{Demographic Data}

The mean age of patients at surgery was 63 years (range 
30-89 years). There were no significant differences in baseline characteristics between patients with CSM who were included $(\mathrm{n}=92)$ and those who were excluded due to incomplete data $(\mathrm{n}=32)$ (Table 1). The surgical levels were as follows: C3-7 in 64 cases; $\mathrm{C} 2-7$ in 19 cases; C3-T1 in 3 cases; C3-6 in 3 cases; C2-6 in 2 cases; and C4-7 in 1 case.

\section{Radiological Results}

The average cervical ROM was $38.8^{\circ}$ (range $6.6^{\circ}-$ $70.8^{\circ}$ ) before surgery and $22.4^{\circ}$ (range $0^{\circ}-57.4^{\circ}$ ) 2 years after surgery. The average rate of reduction of cervical ROM was $40.1 \%$ (range $-34.6 \%$ to $100 \%$ ). Postoperative interlaminar fusion was observed in 60 cases, 52 (86.7\%) of which were observed at the C2-3 level. The average number of fused segments in the fusion group was 1.5 (range 1-6 segments). Among 50 cases in which the T-1 slope was measurable from both the CT scan and the radiograph, the mean T-1 slope on CT scans was $25.9^{\circ} \pm 9.5^{\circ}$ (range $2.4^{\circ}-46.8^{\circ}$ ), and the mean T-1 slope on radiographs was $26.9^{\circ} \pm 9.2^{\circ}\left(\right.$ range $\left.5.3^{\circ}-48.7^{\circ}\right)$. The $\mathrm{T}-1$ slope on CT scans had significant correlations with that on radiographs (Pearson's correlation coefficient $=0.69 ; \mathrm{p}<0.0001$ ), and this was compatible with the results of a previous report. ${ }^{9}$ Therefore, we believe that T-1 slope measurement on CT scans is a valid method.

\section{Differences in Each Variable Between the Fusion and Nonfusion Groups}

Table 2 shows the differences between the fusion and nonfusion groups. Patients in the fusion group were significantly older, had significantly larger C2-7 angles in the flexion position, and had significantly smaller preoperative cervical ROM than those in the nonfusion group. High T-1 slope was significantly more frequent in the fusion group.

\section{Multivariate Analysis of Variables That Predicted Interlaminar Bony Fusion After Laminoplasty}

From the results of the univariate analyses, age, $\mathrm{C} 2-7$ angle in flexion, preoperative cervical ROM, and T-1 slope (high/low) were considered dependent variables. None of the variance inflation factor values exceeded 10 , which indicated that there was no collinearity in the model. ${ }^{3} \mathrm{~A}$ high T-1 slope was a significant risk factor for developing postoperative interlaminar bony fusion (OR $4.8 ; 95 \%$ CI $1.8-13.9 ; \mathrm{p}<0.05$ ) (Table 3), even after adjusting for other risk factors. Older age was also a significant risk factor for developing postoperative interlaminar bony fusion (OR $1.05 ; 95 \%$ CI 1.01-1.10; $\mathrm{p}<0.05)$.

\section{Surgical Outcomes}

The average JOA score was 10.3 (range 5-15) before surgery and 13.4 (range 5-17) 2 years after surgery. The average JOA recovery rate 2 years after surgery was $46.1 \%$ (range $-9.1 \%$ to $100 \%$ ). Table 4 shows the differences in surgical outcomes between the fusion and nonfusion groups. No significant differences were observed in the JOA recovery rate between the fusion and nonfusion groups ( $45 \%$ vs $48 \%$; $p=0.73$ ). However, patients in the fusion group had significantly reduced postoperative cer-
TABLE 1. Differences in baseline characteristics between included and excluded patients

\begin{tabular}{lccc}
\hline \multicolumn{1}{c}{ Variable } & $\begin{array}{c}\text { Patients } \\
\text { Included }\end{array}$ & $\begin{array}{c}\text { Patients } \\
\text { Excluded for } \\
\text { Incomplete Data }\end{array}$ & $\begin{array}{c}p \\
\text { Value }\end{array}$ \\
\hline No. of patients & 92 & 32 & \\
\hline Age in yrs, mean \pm SD & $63.5 \pm 11.8$ & $64.2 \pm 10.1$ & 0.77 \\
\hline Male sex, no. (\%) & $63(68)$ & $26(81)$ & 0.25 \\
\hline Diabetes mellitus, no. (\%) & $19(21)$ & $7 / 30(23)$ & 0.80 \\
\hline Currently smoking, no. (\%) & $21(23)$ & $6 / 26(23)$ & 1.0 \\
\hline $\begin{array}{l}\text { C-2 lamina included in the } \\
\text { surgical treatment, no. (\%) }\end{array}$ & $21(23)$ & $8 / 31(26)$ & 0.81 \\
\hline Preop JOA score, mean \pm SD & $10.3 \pm 2.4$ & $9.8 \pm 2.9(\mathrm{n}=29)$ & 0.31 \\
\hline
\end{tabular}

Continuous variables were compared using the Student t-test or the Wilcoxon rank-sum test; categorical data were analyzed using the chi-square test.

vical ROM compared with those in the nonfusion group (50\% vs $25 \%$; $\mathrm{p}<0.001)$.

\section{Discussion}

In this study, 2 important clinical observations were made. First, high T-1 slope and older age were significant risk factors for developing interlaminar bony fusions after cervical laminoplasty in patients with CSM. Second, the presence of postoperative interlaminar bony fusion was associated with reduced postoperative cervical ROM, but it did not affect neurological outcomes.

T-1 slope was found to be a significant risk factor for developing interlaminar bony fusions after cervical laminoplasty in patients with CSM. A plausible explanation could

TABLE 2. Differences in demographic data and radiographic findings between the fusion and nonfusion groups

\begin{tabular}{|c|c|c|c|}
\hline Variable & $\begin{array}{l}\text { Fusion } \\
\text { Group }\end{array}$ & $\begin{array}{l}\text { Nonfusion } \\
\text { Group }\end{array}$ & $\begin{array}{c}p \\
\text { Value }\end{array}$ \\
\hline No. of patients & 60 & 32 & \\
\hline Male sex, no. (\%) & $38(63)$ & $25(78)$ & 0.15 \\
\hline Diabetes mellitus, no. (\%) & $12(20)$ & $7(22)$ & 0.83 \\
\hline Currently smoking, no. (\%) & $13(22)$ & $8(25)$ & 0.80 \\
\hline $\begin{array}{l}\text { Surgical involvement of the } \\
\text { C-2 lamina, no. (\%) }\end{array}$ & $14(23)$ & $7(22)$ & 0.87 \\
\hline Age in yrs, mean $\pm S D$ & $65.7 \pm 11.0$ & $59.2 \pm 12.3$ & 0.011 \\
\hline \multicolumn{4}{|l|}{$\begin{array}{l}\text { Radiographic parameters, } \\
\text { mean } \pm \text { SD }\end{array}$} \\
\hline C2-7 angle (flexion) & $-11.9 \pm 13.8$ & $-18.8 \pm 10.1$ & 0.016 \\
\hline C2-7 angle (neutral) & $13.1 \pm 13.0$ & $9.6 \pm 10.5$ & 0.19 \\
\hline C2-7 angle (extension) & $25.1 \pm 12.5$ & $23.5 \pm 11.0$ & 0.54 \\
\hline $\begin{array}{l}\text { Preop cervical ROM, mean } \\
\quad \pm \mathrm{SD}\end{array}$ & $37.0 \pm 10.9$ & $42.3 \pm 13.7$ & 0.048 \\
\hline High T-1 slope, no. (\%) & $42(70)$ & $11(34)$ & $<0.0001$ \\
\hline
\end{tabular}

Continuous variables were compared using the Student t-test; categorical data were analyzed using the chi-square test or Fisher's exact probability test. Significant values are $p<0.05$. 
TABLE 3. Multivariate logistic regression analysis of the variables that predicted interlaminar bony fusion after laminoplasty

\begin{tabular}{lccl}
\hline \multicolumn{1}{c}{ Variable } & OR & $95 \% \mathrm{Cl}$ & $\mathrm{p} \mathrm{Value}$ \\
\hline Age & 1.05 & $1.01-1.10$ & 0.025 \\
\hline C2-7 angle (flexion) & 1.01 & $0.96-1.06$ & 0.64 \\
\hline Preop cervical ROM & 0.97 & $0.92-1.01$ & 0.18 \\
\hline High T-1 slope & 4.81 & $1.80-13.9$ & 0.0015 \\
\hline
\end{tabular}

Significant values are $p<0.05$

be inferred from differences in compensatory mechanisms for maintaining cervical alignment between patients with high T-1 slope and those with low T-1 slope. T-1 slope is a known predictor of whole sagittal balance, ${ }^{13}$ whereas high T-1 slope is associated with cervical lordosis to maintain horizontal gaze. ${ }^{15}$ On one hand, patients with high T-1 slope required more cervical lordosis to retain a horizontal gaze, resulting in a prolonged duration for which the cervical laminae were close to each other (Fig. 3 left). On the other hand, patients with low T-1 slope did not need to keep the cervical spine lordotic, unlike those with high T-1 slope; this resulted in cervical laminae that were farther apart (Fig. 3 right). It seems reasonable that laminae closer to each other were more likely to become fused after cervical laminoplasty.

Although the T-1 slope has been reported to be significantly correlated with the $\mathrm{C} 2-7$ angle, ${ }^{15}$ the $\mathrm{T}-1$ slope - not the C2-7 angle in each cervical position-was the significant predictor of postoperative interlaminar bony fusion in the multivariate analysis. Measurement of the C2-7 angle in each position was performed at a single point and may have been substantially affected by CSM-related factors, such as preoperative neck pain or preexisting spinal cord compression. T-1 slope was thought, however, to be a more constant parameter that was not affected by these CSMrelated factors. This difference possibly contributed to the result that the $\mathrm{T}-1$ slope-not the $\mathrm{C} 2-7$ angle-was the significant predictor of postoperative interlaminar bony fusion.

Older age was also found to be a significant risk factor for postoperative interlaminar bony fusion. Similarly, a previous study in patients with CSM following cervical laminoplasty showed that those with postoperative interlaminar bony fusion were significantly older than those without bony fusion. ${ }^{6}$ The authors speculated that reduced preoperative cervical ROM, which was associated with older age, contributed to this result. In our study, however,

TABLE 4. Differences in surgical outcomes between the fusion and nonfusion groups

\begin{tabular}{cccc}
\hline Variable & $\begin{array}{c}\text { Fusion } \\
\text { Group }\end{array}$ & $\begin{array}{c}\text { Nonfusion } \\
\text { Group }\end{array}$ & $\begin{array}{c}\mathrm{p} \\
\text { Value }\end{array}$ \\
\hline JOARR, mean \pm SD $(\%)$ & $45.4 \pm 25.8$ & $47.6 \pm 35.0$ & 0.73 \\
\hline $\begin{array}{c}\text { Reduction rate of cervical } \\
\text { ROM, mean } \pm \text { SD }(\%)\end{array}$ & $49.9 \pm 33.0$ & $25.0 \pm 27.3$ & 0.0007 \\
\hline
\end{tabular}

JOARR $=$ JOA recovery rate.

Significant values are $p<0.05$.

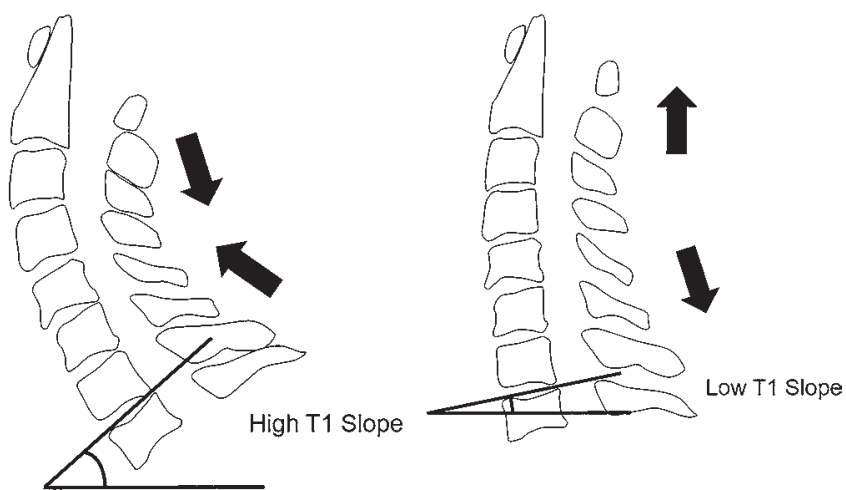

FIG. 3. Illustration of the differences in interlaminar distance between patients with high T-1 slope and those with low T-1 slope. Left: Patients with high T-1 slope require more cervical lordosis to keep a horizontal gaze, resulting in cervical lamina being closer to each other. Right: $\mathrm{Pa}$ tients with low T-1 slope do not need to keep the cervical spine lordotic, resulting in cervical laminae being farther apart.

older age was a significant risk factor even after adjusting for preoperative cervical ROM. Although the actual pathophysiology remains unknown, older patients may be less willing to participate in aggressive postoperative rehabilitation, thereby possibly predisposing them to suffer postoperative interlaminar bony fusion more frequently.

Our study revealed that the presence of postoperative interlaminar bony fusion was associated with reduced postoperative cervical ROM, but it did not affect neurological outcomes. Several previous studies similarly reported that the presence of postoperative interlaminar bony fusion was associated with reduced postoperative cervical ROM. ${ }^{5,6,10,16}$ Regarding neurological outcomes, 1 retrospective study reported that interlaminar bony fusion did not influence neurological recovery after cervical laminoplasty. ${ }^{6}$ Considering these results, the occurrence of postoperative interlaminar bony fusion could be the major contributor to postoperative reduction of cervical ROM, but it did not seem to affect neurological recovery after cervical laminoplasty. Whether the reduction of postoperative cervical ROM affects postoperative axial pain remains controversial. ${ }^{20}$ Some previous studies reported that the occurrence of interlaminar bony fusion was associated with postoperative axial pain. ${ }^{11,12}$ Therefore, the presence of interlaminar bony fusion possibly affects health-related quality of life (HRQOL) outcomes, such as the Neck Disability Index ${ }^{18}$ and the 36-Item Short-Form Health Survey. ${ }^{21}$ Future prospective studies are needed to elucidate whether interlaminar bony fusion affects HRQOL outcomes.

The next issue to be resolved is prevention of postoperative interlaminar bony fusion. Laminectomy of the C-3 lamina is thought to be one of the top options because the base bed laminae are theoretically removed and C2-3 is the most frequently involved level. Furthermore, C-3 laminectomy with C4-7 cervical laminoplasty was reported to show the same neurological outcome as that of $\mathrm{C} 3-7$ cervical laminoplasty and was associated with reduced postoperative axial pain. ${ }^{17}$ Therefore, C-3 laminectomy combined with cervical laminoplasty can be an option to prevent postoperative interlaminar bony fusion, especially when patients are old and have high T-1 slope. Future com- 
parative study is needed to elucidate whether C-3 laminectomy actually prevents the occurrence of postoperative interlaminar bony fusion and improves surgical outcomes.

There were several limitations to this study. First, all patients in our cohort wore a soft collar for 1-2 weeks postoperatively. Because such immobilization provided by the collar could have increased the likelihood of postoperative interlaminar bony fusion, ${ }^{7}$ we must be careful in interpreting the results. However, the actual incidence of postoperative interlaminar bony fusion was $65 \%$ in our study, which is comparable with that reported previously (53\%-66\%). Therefore, we believe that postoperative use of a soft collar for 1-2 weeks did not dramatically increase the occurrence of postoperative interlaminar bony fusion. Second, the effects of interlaminar bony fusion on HRQOL outcomes, such as the Neck Disability Index and the 36-Item Short-Form Health Survey, were not evaluated. Future prospective studies are required to elucidate this issue. Third, the occurrence of interlaminar bony fusion in our study was possibly overestimated because there may have been some cases in which spontaneous interlaminar bony fusion developed regardless of the surgery.

\section{Conclusions}

High T-1 slope and older age were risk factors for developing interlaminar bony fusion after cervical laminoplasty in patients with CSM. Interlaminar bony fusion was associated with reduced postoperative cervical ROM, but it did not affect neurological outcomes. Identification of these factors may help provide appropriate information on patients with CSM. Future comparative studies that investigate the most appropriate surgical procedure to prevent postoperative interlaminar bony fusion are warranted.

\section{References}

1. Chiba K, Ogawa Y, Ishii K, Takaishi H, Nakamura M, Maruiwa H, et al: Long-term results of expansive open-door laminoplasty for cervical myelopathy-average 14-year follow-up study. Spine (Phila Pa 1976) 31:2998-3005, 2006

2. Gu Y, Cao P, Gao R, Tian Y, Liang L, Wang C, et al: Incidence and risk factors of C5 palsy following posterior cervical decompression: a systematic review. PLoS One 9:e101933, 2014

3. Hair JF Jr, Anderson R, Tatham R, Black WC: Multivariate Data Analysis, ed 3. New York: Macmillan, 1995

4. Hirabayashi K, Miyakawa J, Satomi K, Maruyama T, Wakano K: Operative results and postoperative progression of ossification among patients with ossification of cervical posterior longitudinal ligament. Spine (Phila Pa 1976) 6:354-364, 1981

5. Hyun SJ, Riew KD, Rhim SC: Range of motion loss after cervical laminoplasty: a prospective study with minimum 5-year follow-up data. Spine J 13:384-390, 2013

6. Iizuka H, Iizuka Y, Nakagawa Y, Nakajima T, Toda N, Shimegi A, et al: Interlaminar bony fusion after cervical laminoplasty: its characteristics and relationship with clinical results. Spine (Phila Pa 1976) 31:644-647, 2006

7. Iizuka H, Nakagawa Y, Shimegi A, Tsutsumi S, Toda N, Takagishi K, et al: Clinical results after cervical laminoplasty: differences due to the duration of wearing a cervical collar. $\mathbf{J}$ Spinal Disord Tech 18:489-491, 2005

8. Japanese Orthopaedic Association: Scoring system for cervical myelopathy. Nippon Seikeigeka Gakkai Zasshi 68:490503,1994
9. Jun HS, Chang IB, Song JH, Kim TH, Park MS, Kim SW, et al: Is it possible to evaluate the parameters of cervical sagittal alignment on cervical computed tomographic scans? Spine (Phila Pa 1976) 39:E630-E636, 2014

10. Kawaguchi Y, Kanamori M, Ishihara H, Ohmori K, Abe Y, Kimura T: Pathomechanism of myelopathy and surgical results of laminoplasty in elderly patients with cervical spondylosis. Spine (Phila Pa 1976) 28:2209-2214, 2003

11. Kawaguchi Y, Kanamori M, Ishihara H, Ohmori K, Nakamura H, Kimura T: Minimum 10-year followup after en bloc cervical laminoplasty. Clin Orthop Relat Res (411):129139,2003

12. Kawaguchi Y, Matsui H, Ishihara H, Gejo R, Yoshino O: Axial symptoms after en bloc cervical laminoplasty. J Spinal Disord 12:392-395, 1999

13. Knott PT, Mardjetko SM, Techy F: The use of the T1 sagittal angle in predicting overall sagittal balance of the spine. Spine J 10:994-998, 2010

14. Kurokawa T, Tsuyama N, Tanaka H, Kobayashi H, Machida $\mathrm{H}$, Nakamura K, et al: [Enlargement of spinal canal by sagittal splitting of the spinal process.] Bessatsu Seikeigeka 2:234-240, 1982 (Jpn)

15. Lee SH, Kim KT, Seo EM, Suk KS, Kwack YH, Son ES: The influence of thoracic inlet alignment on the craniocervical sagittal balance in asymptomatic adults. J Spinal Disord Tech 25:E41-E47, 2012

16. Seichi A, Takeshita K, Ohishi I, Kawaguchi H, Akune T, Anamizu Y, et al: Long-term results of double-door laminoplasty for cervical stenotic myelopathy. Spine (Phila Pa 1976) 26:479-487, 2001

17. Takeuchi K, Yokoyama T, Aburakawa S, Saito A, Numasawa $\mathrm{T}$, Iwasaki T, et al: Axial symptoms after cervical laminoplasty with C3 laminectomy compared with conventional C3-C7 laminoplasty: a modified laminoplasty preserving the semispinalis cervicis inserted into axis. Spine (Phila Pa 1976) 30:2544-2549, 2005

18. Vernon H, Mior S: The Neck Disability Index: a study of reliability and validity. J Manipulative Physiol Ther 14:409415, 1991

19. Wada E, Suzuki S, Kanazawa A, Matsuoka T, Miyamoto S, Yonenobu K: Subtotal corpectomy versus laminoplasty for multilevel cervical spondylotic myelopathy: a longterm follow-up study over 10 years. Spine (Phila Pa 1976) 26:1443-1448, 2001

20. Wang SJ, Jiang SD, Jiang LS, Dai LY: Axial pain after posterior cervical spine surgery: a systematic review. Eur Spine J 20:185-194, 2011

21. Ware JE Jr: SF-36 health survey update. Spine (Phila Pa 1976) 25:3130-3139, 2000

\section{Disclosures}

The authors report no conflict of interest concerning the materials or methods used in this study or the findings specified in this paper.

\section{Author Contributions}

Conception and design: Oichi. Acquisition of data: Oichi, Takeshita. Analysis and interpretation of data: Oichi, Oka. Drafting the article: Oichi. Critically revising the article: Oshima. Reviewed submitted version of manuscript: all authors. Statistical analysis: Oichi, Oka. Study supervision: Oshima, Tanaka.

\section{Correspondence}

Yasushi Oshima, Department of Orthopaedic Surgery, The University of Tokyo Hospital, 7-3-1 Hongo, Bunkyo-ku, Tokyo 1138655, Japan. email: yoo-tky@umin.ac.jp. 